\title{
Neuroradiologists and the Novel Coronavirus
}

W e wish to extend our gratitude to Drs Mahajan and Hirsch for their succinct and informative editorial on the novel coronavirus, COVID-19. ${ }^{1}$ The editorial staff at the American Journal of Neuroradiology, at large, should also be recognized for broadening the focus of the journal and publishing an accessible, timely, and factual review.

The authors successfully combat uncertainty with science and objective guidance. Their underlying message is critically important. Specifically, all medical professionals-even those in highly subspecialized fields like neuroradiology-must rededicate themselves to the broader goal of promoting public health. The information presented provides a roadmap as we struggle to identify our role in this extraordinary time. While fiscally challenging and counter to the precoronavirus conceptualizations of our professio-

- Indicates open access to non-subscribers at www.ajnr.org http://dx.doi.org/10.3174/ajnr.A6596 nal responsibility, this may entail promotion of social distancing by placing some of our patient care (for instance, routine outpatient imaging) on hold.

Drs Mahajan and Hirsch are to be commended for educating the neuroradiology community about an issue that impacts us in and outside of the reading room. They have provided a helpful resource, which can enhance our care of patients, friends, family, and ourselves during the challenging days ahead. Thank you.

\section{REFERENCE}

1. Mahajan A, Hirsch JA. Novel coronavirus: what neuroradiologists as citizens of the world need to know. AJNR Am J Neuroradiol 2020;41:552-54 CrossRef Medline

U. Antonucci

(D) J.M. Reagan

(D) Mazdani Department of Radiology and Radiological Science Medical University of South Carolina Charleston, South Carolina 